\title{
Monetary Rules: Theory and Practice
}

Frameworks for Central Banking in the Next Century Policy Conference

Hoover Institution

Stanford, CA

May 30, 2014

\author{
Charles I. Plosser \\ President and CEO \\ Federal Reserve Bank of Philadelphia
}

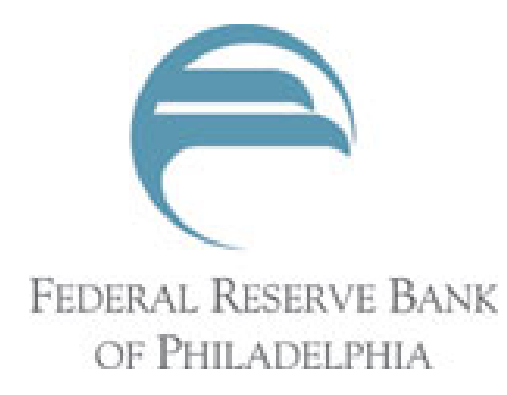

The views expressed today are my own and not necessarily those of the Federal Reserve System or the FOMC. 


\section{Monetary Rules: Theory and Practice \\ Frameworks for Central Banking in the Next Century Policy Conference Hoover Institution \\ Stanford, CA}

May 30, 2014

Charles I. Plosser

President and Chief Executive Officer

Federal Reserve Bank of Philadelphia

\section{Highlights}

- President Charles Plosser discusses his views on the benefits of a systematic and rule-like approach to monetary policy.

- President Plosser outlines his proposals to indicate the likely behavior of the policy rate based on a few different Taylor-like rules that have been consistent with past conduct of monetary policy and are robust to our uncertainties regarding the true economic model.

- President Plosser believes that the model created by the Federal Reserve Board staff, called FRB/US, seems to be a reasonable starting point for providing economic forecasts based on those rule-based policies; however, other models would be useful to consider.

Note: President Plosser presented related remarks on May 28, 2014, at the 2014 Bank of JapanInstitute for Monetary and Economic Studies Conference.

\section{Introduction}

I would like to thank John Taylor for inviting me to participate in this panel discussion about a subject that I feel is very important. Rules-based policy is a topic that I have discussed numerous times in the past few years, urging policymakers to seek a more systematic approach to policymaking. I am particularly honored to be on a panel with my colleague John Williams, whose research in this area has been an important influence on my views, as well as Tom Sargent. In Tom's case, there probably isn't an economist in this room who hasn't been 
influenced by his work and his contributions to economics. But before I go any further, I should begin with the usual disclaimer that my views are my own and do not necessarily reflect those of the Federal Reserve System or my colleagues on the Federal Open Market Committee (FOMC).

\section{The Theoretical Justification for Rules}

The theory part of this session's title is well established. In their Nobel Prize-winning work, Finn Kydland and Ed Prescott demonstrated that a credible commitment by policymakers to behave in a systematic, rule-like manner over time leads to better outcomes than discretion. ${ }^{1}$ Since then, numerous papers using a variety of models have investigated the benefits of rule-like behavior in monetary policy and found that there are indeed significant benefits. ${ }^{2}$ Policies characterized by commitment have been shown to lead to more economic stability - lower and less volatile inflation and less volatile output. In fact, the mainstream theoretical models that we use for monetary and macroeconomic analysis are built on the notion that monetary policy is conducted in a rule-like manner.

\section{The Practice}

The practice part of the session title has proven to be a bit more elusive. The science of monetary policy has not progressed to the point where we can specify the optimal rule for setting monetary policy. The reason is that optimal rules, that is, those that maximize economic welfare, are highly dependent on the particular model from which they are derived, and there is no broad-based consensus for the right model. More relevant is the finding that the optimal rule for one model can produce very bad outcomes in another model. In addition, optimal rules can often be quite complex, thus making them difficult to implement and to communicate to the public. In other words, they may not be very transparent.

\footnotetext{
${ }^{1}$ Finn E. Kydland and Edward C. Prescott, "Rules Rather than Discretion: The Inconsistency of Optimal Plans," Journal of Political Economy, 85 (June 1977), pp. 473-91.

2 For an excellent overview, see Richard Clarida, Jordi Gali, and Mark Gertler, "The Science of Monetary Policy," Journal of Economic Literature (December 1999), pp. 1661-1707.
} 
However, these limitations to implementing optimal policy rules should not deter us from efforts to adopt a more systematic rule-like approach to the conduct of policy. There has been a great deal of progress made in identifying simple rules that appear to perform well in a variety of models and environments. Such robust rules can form a basis for developing more systematic, rule-like policymaking.

One important and desirable characteristic of a systematic and rule-like approach to policy relates to communication. In particular, it is an approach that is easily communicated to the public and thus greatly improves the transparency and predictability of monetary policy, which reduces surprises. The public and markets are more informed about the course of monetary policy because they understand how policymakers are likely to react to changing economic circumstances. Equally important in my view is that greater clarity about the policymakers' reaction function strengthens accountability and thus can serve to preserve the central bank's independence.

The most well-known simple rule, of course, is the one proposed by John Taylor in $1993 .^{3}$ The Taylor rule and the family of rules it has inspired call for setting the nominal fed funds rate based on three factors: the economy's long-run real interest rate plus the Fed's target rate of inflation, the deviation of inflation from the central bank's target, and the departure of real GDP from some measure of "potential" GDP. The rule implies, for example, that when inflation is above target, the funds rate should increase by more than one-for-one with the deviation, and when GDP is below "potential," the funds rate should be reduced.

The attractiveness of Taylor-like rules for monetary policy goes beyond their intuitive appeal or the fact that they seem to describe the actual behavior of monetary policy reasonably well. Taylor-like rules tend to fall in the class of those rules that are robust. That is, they yield good

\footnotetext{
3 John B. Taylor, "Discretion Versus Policy Rules in Practice," Carnegie-Rochester Series on Public Policy, NorthHolland, 39, 1993, pp. 195-214.
} 
results in a variety of theoretical settings. This feature is of enormous practical importance. Given our uncertainty about the true model of the economy, knowing that systematic policy in the form of a Taylor-like rule delivers good outcomes in a variety of models means that simple, robust rules can provide useful guidance for policy.

Given model uncertainty and data measurement problems, there are, of course, limitations to the use of a simple rule. The rule is basically intended to work well on average, but central banks look at many variables in determining policy. There inevitably will be times when economic developments fall outside the scope of our models and warrant unusual monetary policy action. Events such as 9/11, the Asian financial crisis, the collapse of Lehman Brothers, and the 1987 stock market crash may require departures from a simple rule. Having articulated a rule guiding policymaking in normal times, however, policymakers will be expected to explain the departures from the rule in these unusual circumstances. With a rule as a baseline, departures can be quantified and inform us how excessively tight or easy policy might be relative to normal. If the events are temporary, policymakers will have to explain how and when policy is likely to return to normal. Thus, a simple rule provides a valuable benchmark for assessing the appropriate stance of policy. That makes it a useful tool to enhance effective communication and transparency.

\section{Rules and Forward Guidance}

In addition to providing important guidance for current policy decisions, Taylor-like rules can also be extremely useful in providing guidance for the expected future path of policy. Such forward guidance has received a good deal of attention recently. One reason for this increased attention is that short-term rates have been constrained by the zero lower bound. Thus, forward guidance and communication regarding future policy decisions take on greater significance.

However, forward guidance is not a separate or independent policy tool. Its effectiveness is intimately related to other features of monetary policy. Monetary policy should be thought of 
more holistically, if you will. How effective we are with forward guidance, for example, can only be assessed or thought of in the context of a central bank's overall approach to policy, including its approach to communication and transparency.

In particular, I see a credible, rule-like approach to policy and the general openness and transparency of the policy process as essential elements in shaping expectations. Indeed, a commitment to a policy framework that is systematic and rule-like provides the foundation for establishing expectations concerning the future path of policy and thus forward guidance.

\section{Rules as Benchmarks: A Step Forward}

So from my perspective, using Taylor-like rules to shape current and expected future policy is an important and useful part of any monetary policy framework. The operational question is how might one go about such an effort? This is not a trivial assignment. As I mentioned at the outset, it has proved to be quite elusive.

In a stylized world, where there is a single monetary policymaker who has considerable confidence in a model of the economy, communication would include a forecast derived from this model. This forecast would incorporate a policy path that yields the best economic outcomes based on that single policymaker's views.

Unfortunately, we don't live in such a world. Monetary policymaking is often conducted by committee, and divergent views can and often do exist. While this can be clumsy at times, such governance mechanisms ensure that various views are heard in an environment that promotes better decisions and better outcomes.

Nevertheless, I believe that given the nature of U.S. institutional arrangements, Taylor-like rules can serve a very useful purpose. Specifically, they could underpin the construction of a periodic detailed monetary policy report, a feature of communication that has been adopted by many 
central banks around the world. However, while these reports have many similarities, there are some key differences.

Many central banks include detailed forecasts in their published reports and highlight risks along with the outlook. This communication about the evolution of key economic variables that shape policy is important, but there is still debate about the nature of the forecasts and the assumptions that underlie them.

A critical piece of a forecast emanating from the central bank is the nature of the future path of the policy rate. Should a central bank's published forecast be based on its assessment of what the policy rate path is likely to be, perhaps based on its reaction function, or should the forecast be based on an interest rate path that is more arbitrary, such as a constant interest rate path or one that is related to market expectations?

An alternative approach that could easily be adopted would be to indicate the likely behavior of interest rates based on a few different Taylor-like rules that have been consistent with the conduct of monetary policy in the past or ones that are considered robust across various models of the economy. Doing so would require agreement on a particular model in order to produce the resulting rule-based behavior. For the Fed, the economic model developed by the Board's staff, called FRB/US, seems like a reasonable place to start. Such an exercise could also be enhanced, I believe, by using some of the dynamic stochastic general equilibrium, or DSGE, models that have been developed within the Federal Reserve System.

The FOMC could then use its biannual monetary policy reports to communicate the results and whether and why it anticipates policy to be somewhat more restrained or more accommodative relative to the projections given by the various rules. The monetary policy report could also include various views that may differ from the baseline summaries. Policy statements between reports can refer back to the reports to provide consistency in the Committee's communications with the public. 
Performing this exercise would illustrate the various dimensions of uncertainty that policymakers face. For example, there is model uncertainty, forecast uncertainty, and the variations implied by different rules. Many central banks use fan charts and other devices to highlight such bands of uncertainty about the forecast, and the Fed should do the same. It would provide a better sense of the likely direction of policy and the variables most related systematically to that policy. Further, this type of communication would push the FOMC to conduct policy in a more systematic manner, which I believe will lead to better economic outcomes over the longer run.

\section{Conclusions}

I am fully aware that we need to take great care in providing more specific forms of forward guidance so that we avoid a false sense of certainty and a mistaken sense of commitment. Yet, I believe systematic rule-like monetary policymaking can enhance economic performance, and therefore, I favor clearer communication concerning the formulation of policy.

Providing information about how the policy path is likely to evolve forces policymakers to think more deeply and more systematically about policy. Communication about that path, in turn, gives the public a much deeper understanding of the analytical approach that guides monetary policy. 